\title{
Migrated endoclip removal after cholecystectomy under digital single-operator cholangioscopy guidance
}

Laparoscopic cholecystectomy is now an established treatment for cholecystolithiasis or acute cholecystitis [1-3], but adverse events such as endoclip migration into the biliary tract may occur [4]. Usually, migrated endoclips can be removed by standard bile duct stone removal techniques. However, if endoclips have migrated into the intrahepatic bile duct, removal of the endoclip is sometimes challenging. In addition, bile duct injury may occur during removal [5]. Herein, we describe technical tips for the safe removal of a migrated endoclip under direct digital single-operator cholangioscopy guidance.
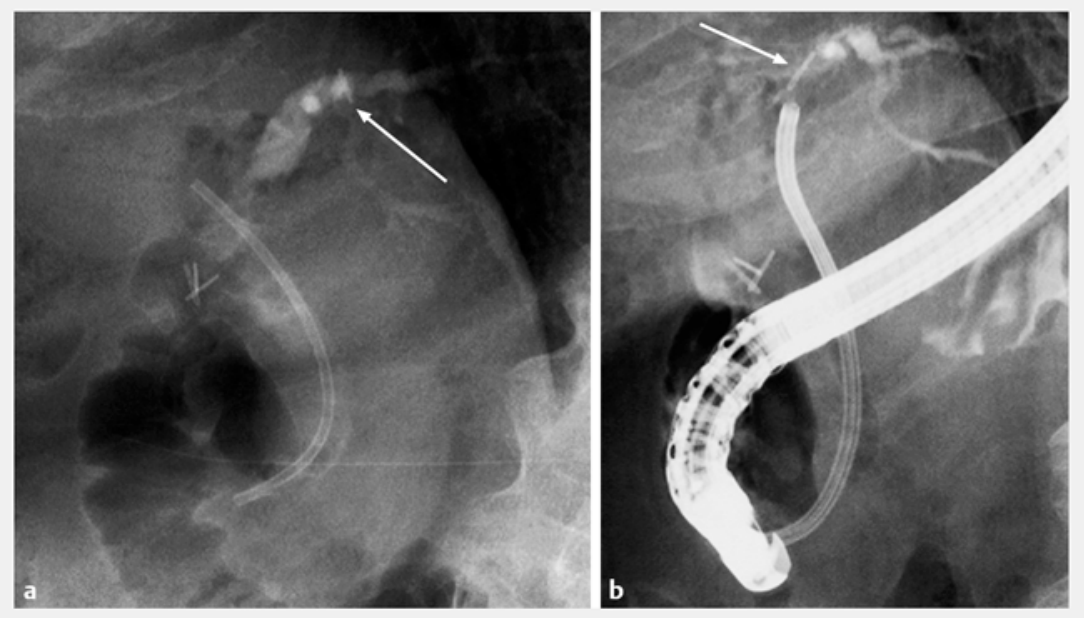

- Fig. 1 Radiographic images showing: a a migrated endoclip in the left intrahepatic bile duct; $\mathbf{b}$ an intraductal cholangioscope (SPY-DS) inserted into the biliary tract (arrow in each image indicates the endoclip).

A 56-year-old man who had undergone cholecystectomy without any adverse events 1 month previously was found during a follow-up computed tomography (CT) scan to have a common bile duct stone. He was therefore admitted for removal of this stone. Endoscopic retrograde cholangiopancreatography (ERCP) was attempted; however, it was observed that there had been endoclip migration into the intrahepatic bile duct ( Fig.1a). Unsuccessful attempts were made to remove the endoclip using standard techniques, such as a balloon or a basket catheter, and he was therefore admitted to our hospital for removal of the migrated endoclip under direct visualization with cholangioscopy.

First, an intraductal cholangioscope (SPY-DS; Boston Scientific, Natick, Massachusetts, USA) was inserted into the common bile duct ( $\triangleright$ Fig.1 b) and the migrated endoclip was clearly observed ( Fig.2a). This migrated clip was grasped by a SPY-Bite device ( $\mathbf{F i g} \mathbf{2} \mathbf{b}$ ) and successfully removed into the duodenum without any adverse events ( $>$ Fig. 2c; Video1). Following this, the SPY-Bite was exchanged for a large
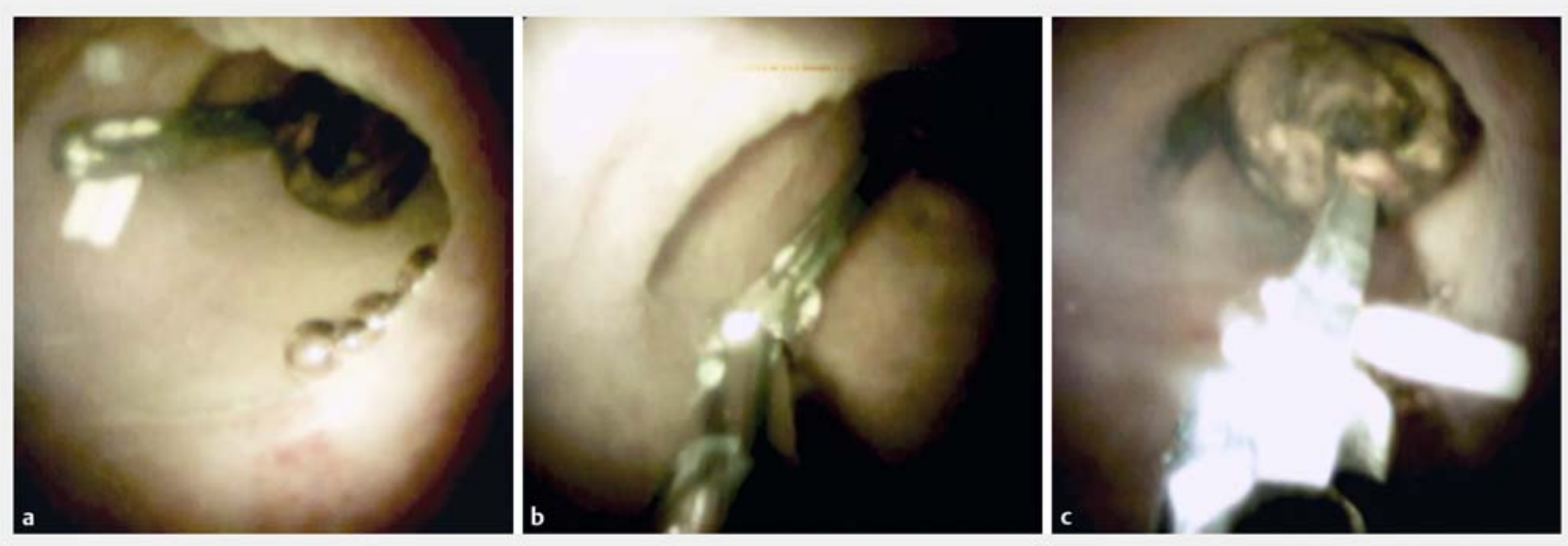

Fig. 2 Cholangioscopic images showing: a the endoclip within the left intrahepatic bile duct; $\mathbf{b}$ the endoclip being grasped by the SPY-Bite device; $c$ the migrated endoclip being successfully removed into the duodenum. 


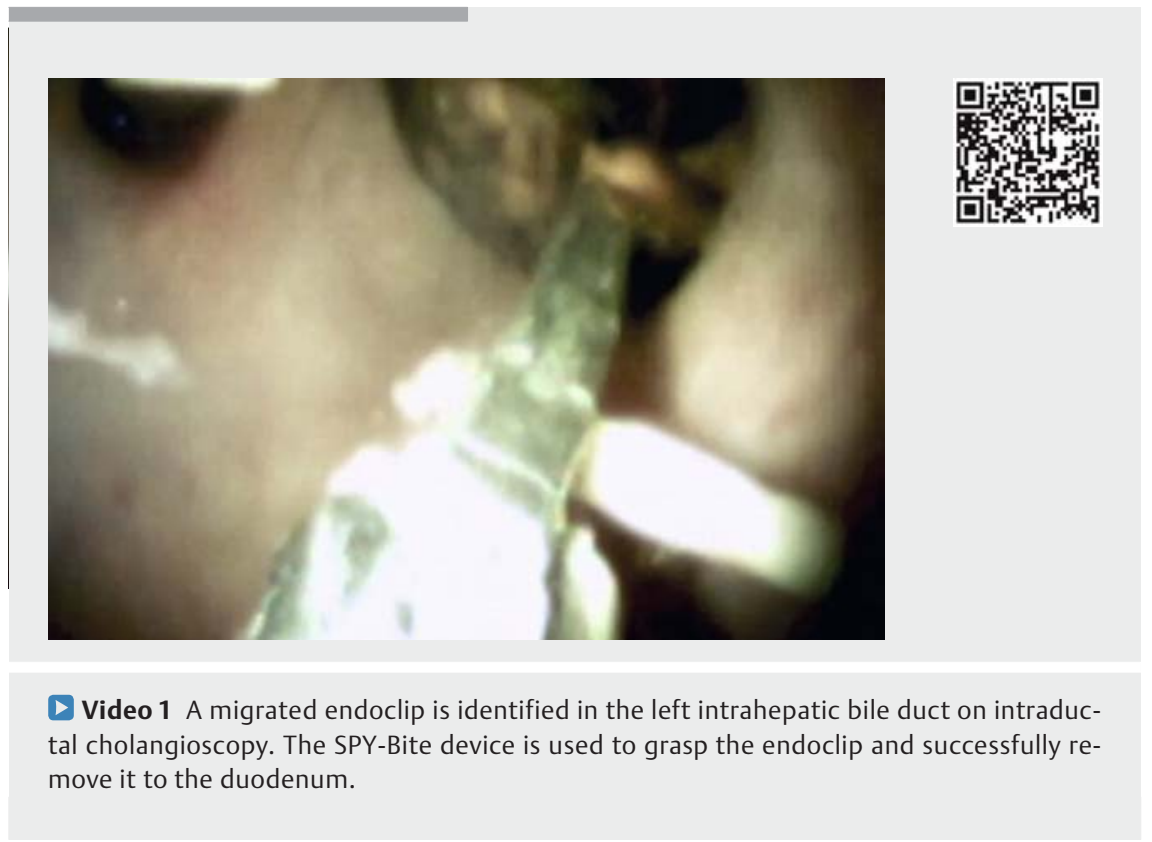

grasping forceps and the clip was extracted.

Our technique for removal of a migrated endoclip proved to be safe in this patient. Direct visualization with the intraductal cholangioscope was helpful in this case because of the four-way bending of the device.

Endoscopy_UCTN_Code_TTT_1AR_2AK

\section{Competing interests}

None
The authors

Takeshi Ogura, Atsushi Okuda, Akira Miyano, Nobu Nishioka, Kazuhide Higuchi

2nd Department of Internal Medicine, Osaka

Medical College, Osaka, Japan

Corresponding author

\section{Takeshi Ogura, MD}

2nd Department of Internal Medicine, Osaka Medical College, 2-7 Daigakuchou, Takatsukishi, Osaka 569-8686, Japan Fax: +81-726-846532

oguratakeshi0411@yahoo.co.jp

[1] Glavic Z, Begic L, Simlesa D et al. Treatment of acute cholecystitis. A comparison of open vs laparoscopic cholecystectomy. Surg Endosc 2001; 15: $398-401$

[2] Coccolini F, Catena F, Pisano M et al. Open versus laparoscopic cholecystectomy in acute cholecystitis. Systematic review and meta-analysis. Int J Surg 2015; 18: 196-204

[3] Brazzelli M, Cruickshank M, Kilonzo M et al. Systematic review of the clinical and cost effectiveness of cholecystectomy versus observation/conservative management for uncomplicated symptomatic gallstones or cholecystitis. Surg Endosc 2015; 29: 637 747

[4] Ahn SI, Lee KY, Kim SJ et al. Surgical clips found at the hepatic duct after laparoscopic cholecystectomy. Surg Laparosc Endosc Percutan Tech 2005; 15: 279-282

[5] Tusmura H, Ichikawa T, Kagawa T et al. Failure of endoscopic removal of common bile duct stones due to endo-clip migration following laparoscopic cholecystectomy. J Hepatobiliary Pancreat Surg 2002; 9: 274-277

\section{Bibliography}

DOI https://doi.org/10.1055/s-0043-124758

Published online: 12.1.2018

Endoscopy 2018; 50: E74-E75

(c) Georg Thieme Verlag KG

Stuttgart · New York

ISSN 0013-726X

\section{ENDOSCOPY E-VIDEOS}

https://eref.thieme.de/e-videos

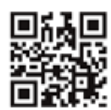
Endoscopy E-Videos is a free access online section, reporting on interesting cases and new

techniques in gastroenterological endoscopy. All papers include a high quality video and all contributions are freely accessible online.

This section has its own submission website at https://mc.manuscriptcentral.com/e-videos 